\title{
Le frère de lait
}

\section{D.Faten El-Elimi}

\section{Sommaire :}

Le titre de la nourrice royale était connu pour la première fois au début de la XVIII ${ }^{\text {ème }}$ dynastie, et n'est plus utilisé après la mort du roi Akhenaton.

La nourrice royale avait occupé une grande position, aussi bien que ses époux et ses enfants, dont les enfants ont eu de très importantes positions dans le pays.

Le roi Thoutmosis III avait choisi son frère de lait 'Menkheperresoneb' d'être " le grand prêtre d'Amon», et aussi Aménophis II avait choisi son frère de lait 'Kenamon' pour occuper une grande position administrative de "grand supervision financière ». Ce choix retourne aux confiances des rois en les enfants de nourricières.

Cette recherche avait l'objective d'étudier le titre de « frère de lait, (s3 $\left.n(y) m n^{\top} t \quad n(y) . s w . t\right) »$, et les titres aussi que les positions occupées par ses personnages parce qu'ils ont été les enfants des nourricières royales. Ce titre joua un grand rôle administratif dans le pays pendant la XVIII ${ }^{\text {ème }}$ dynastie, dont les personnages qui ont reçu ce titre, occupait des grandes positions dans le pays.

\section{Introduction :}

Le titre de 'frère de lait ou sœur de lait' est un titre qui présente une position sociale et une relation de fraternité avec le fils royal à travers l'allaitement et l'éducation d'une seule nourricière'.

Le titre de nourricière n'a pas apparu qu'à la XVIII ${ }^{\text {ème }}$ dynastie, mais les scènes et les inscriptions qui représentent les allaitements (fig. 1$)^{2}$, ses titres et ses fonctions ont été apparues pour la première fois pendant la $\mathrm{V}^{\text {ème }}$ dynastie. (Le rôle de nourricière n'était pas

\footnotetext{
"Maître de conférences à la faculté du tourisme et d'hôtellerie, Université du Canal de Suez ${ }^{1}$ R.Schlichting, "Milch(wirtschaft)", L $\ddot{A}$ IV, p. 127.

${ }^{2}$ R.Schulz, M.Seidel, Egypt the world of the Pharaos, China, 2007, p. 409.
} 
seulement d'allaiter, mais aussi d'éduquer, et d'élever). La première scène d'allaiter, se trouve dans le temple de Sahure de la $V^{\text {ème }}$ dynastie où le roi est entrain d'allaiter de la déesse Nekhbet ${ }^{3}$.

Les célèbres divinités nourricières, d'après les Textes des Pyramides, étaient : Isis, Nephthys, Selket, Neith, Nout, Sekhat-hor, Smaatouret, aussi les deux vautours personnifiant les couronnes royales et les deux vaches noires, nourrices des âmes d'Héliopolis ${ }^{4}$. Quand la déesse allaite le nouveau né, c'est-à-dire préparer le nouveau roi pour monter au trône, l'allaiter par la vie, la prospérité et rester million d'année sur le trône d'Horus ${ }^{5}$ (fig. 2$)^{6}$. Le roi, allaité par une déesse, pour accéder par ce rite à une nouvelle existence, toute divine, où il puisera la force d'assurer, sur cette terre, sa mission souveraine (fig. 3$)^{7}$.

À partir de la première moitié de la XVIII ${ }^{\text {ème }}$ dynastie, les scènes d'allaitement du roi par la déesse Hathor est devenu un célèbre sujet (fig. 4$)^{8}$, surtout pendant le règne d'Hatshepsout et Thoutmosis III (la plupart des scènes représentent le roi jeune, agenouillé et entrain d'allaiter de la déesse vache Hathor (fig.5). On a trouvé aussi des scènes d'allaitement du roi par la déesse Rénénoutet, déesse des moissons (fig.6) ${ }^{10}$.

Le titre de nourricière $\left(m n^{\top} t\right)$ a apparu pour la première fois à la $\mathrm{XVIII}^{\mathrm{e} m e}$ dynastie, puis a disparu totalement à la fin du règne du roi Akhnaton.

${ }^{3}$ L.Borchardt, Das Grabdenkmal des Königs Sahu-re, Leipzig, 1910, pl. 18.

${ }^{4}$ J.Leclant, «Le rôle du lait et de l'allaitement d'après les Textes des Pyramides », JNES 10, 1951, p. 123.

${ }^{5}$ H.Brunner, Altägyptische Erziehung, Wiesbaden, 1957, p. 128.

${ }^{6}$ G.Posener,S.Sauneron et J.Yoyotte,Dictionnaire de la civilisation égyptienne,Paris,1988,p. 140.

${ }^{7}$ Ibid, p. 145.

${ }^{8}$ B.Watterson, Gods of Ancient Egypt, Hong Kong, 1996, p. 116-117.

${ }^{9}$ M.Werbrouck, Le temple d'Hatshepsout à Deir el Bahri, Brussel, 1948.

${ }^{10}$ W.Wreszinski, Atlas Zur altägyptshite, Leipzig, 1923, pl. 198. 
Ce titre $\left(m n^{\top} t\right)$ signifie nourrir, allaiter ou élever, aussi le verbe (hnmt ou $\breve{s} d t)$ donne le même sens de $\left(m n^{`} t\right)$, le titre (hkrt nsw) replaçait le titre de $\left(m n^{`} t\right)$ pendant l'Ancien Empire ${ }^{11}$.

Dès la première moitié de la XVIII ${ }^{\text {ème }}$ dynastie, plusieurs femmes ont pris le titre de nourricière, parmi ses titres : « $m n^{\top} t n s w, m n^{\top} t$ wrt $n n b-t 3 w y$ " qui ont été utilisés jusqu'à la fin du règne d'Akhnaton.

Le rôle de nourricière était d'allaiter l'enfant avec une bonne quantité de son lait. Pendant ce temps elle ne pouvait allaiter aucun autre que le sein. D'ailleurs, elle ne pouvait pas faire aucune relation sexuelle et ne pouvait pas être enceinte durant la période d'allaitement ${ }^{12}$.

Les deux premières nourricières royales étaient: Ray et Tetihemet, ce sont les deux nourricières royales de la reine AhmèsNefertary.

Ray a pris le titre de: «mn`t nt hmt-nțr i`hmms-nfrt-iry $\square$, la nourricière, femme du dieu, Ahmès-Nefertary.

L'autre nourricière, on lui n'a trouvé qu'une seule inscription sur les murs de la tombe (TT 15) de Tetiky à Dra Abou el-Naga, « $m n^{`} t$.s tti- hmt » la nourricière Teti-hemet ${ }^{13}$.

Hatshepsout avait quatre nourricières ; Thoutmosis III avait deux nourricières, dont une (Hepu) était la mère de sa femme royale, la reine Sataha ${ }^{14}$; Aménophis II avait cinq nourricières, en plus de la nourricière de sa femme, la reine Tiaa; Aménophis III avait une nourricière pour sa fille, la princesse Satamon; et Akhnaton avait une seule nourricière de sa femme, la reine Nefertiti.

\section{Document 1 :}

Nom : Satepihu ${ }^{15}$

Famille : fils du nourricière Tinetiunet.

${ }^{11} \mathrm{~Wb}$. II, 77-78.

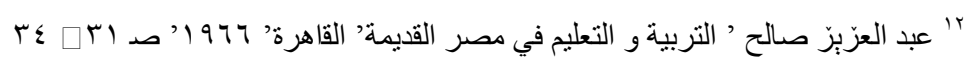

${ }^{13}$ N.de G.Davies,’The tomb of Tetaky at Thebes (No.15)”, JEA 11, 1915, p. 14.

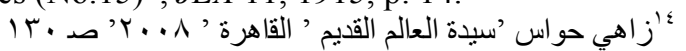

${ }^{15}$ C.Roehrig, The Eightenth dynasty titles royal nurse royal tutor and foster, Michigan, 1996, p.14. 
Époque : XVIII ${ }^{\text {ème }}$ dynastie, règne de Hatshepsout.

Titre : Maire de Thinis (h3ty-` $n$ tny).

Document : stèle d'Abydos ${ }^{16}$, CG 34080(JE 18501).

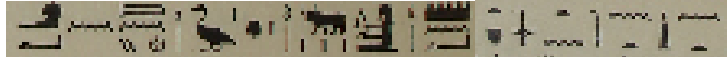

h33ty` $n$ tny s3tp k3w-šps nswt mn't ti-nt-iwnt ${ }^{17}$

"Maire de Thinis, Satepihu, les ka du noble, nourricière royale, Tinetinuet".

\section{Document 2 :}

Nom : Puyemre

Famille : fils du nourricière Nofretiah ${ }^{18}$

Nofretiah a pris le titre de " $m n^{\top} t$ wrt ", la grande nourricière.

Époque : XVIII ${ }^{\text {ème }}$ dynastie, règne de Hatshepsout et de Thoutmosis III.

Titre : Deuxième prêtre d'Amon ( $h m$ n ntr snw n 'Imn $)^{19}$,

il a pris ce titre durant la dernière moitié du règne de Hatshepsout, et pendant tout le règne de Thoumosis III.

Document : Tombe de Puyemre (TT39) ${ }^{20}$.

\section{Document 3 :}

Nom : Hapuseneb

Famille : fils du nourricière Ahahotep

Ahahotep a pris le titre de " $m n^{\top} t-n s w »$, la nourricière du roi.

Époque : XVIII ${ }^{\text {ème }}$ dynastie, règne de Hatshepsout

Titre : Grand prêtre d'Amon ${ }^{21}$.

\section{Document 4 :}

Nom : Menkheperresonb

Famille : fils du nourricière Taiunet.

\footnotetext{
${ }^{16}$ A. Mariette, Monuments d'Abydos, p. 393-394 ; P.Lacau, Stèles du Nouvel Empire, catalogue général des antiquités égyptiennes du Musée du Caire, Le Caire, 1909, p. 127-129, pl. XLI.

${ }^{17}$ P.Lacau, op.cit, p. 128.

${ }^{18}$ C.Roehrig, The Eightenth dynasty titles royal nurse royal tutor and foster, Michigan, 1996, p.28.

${ }^{19}$ N.de G. Davies, The Tomb of Puyemere ${ }^{c}$ at Thebes, t.I, London, 1922, p. 19-20.

${ }^{20}$ PM I 1, p.71-75.

${ }^{21}$ H.Kees, DasPriestertum im Ägyptischen Staat vom Neuen Reich bis zur Spätzeit, Leiden, 1953, p. 10.
} 
Taiunet a pris le titre de " $m n^{\top} t-n s w$ ", la nourricière du roi, car sa mère Nebetta était sœur du lait du roi Thoutmosis I. Époque : XVIII ${ }^{\text {ème }}$ dynastie, règne de Thoutmosis III.

Titre : Grand prêtre d'Amon

Document: Tombe de Menkheperresonb (TT 112) 22 ; statue (CG 42125) (fig.7) trouvé à Karnak ${ }^{23}$.

\section{Document 5 :}

Nom : Ahmose

Famille : fils du nourricière.

Le nom de sa mère est inconnu, on a trouvé seulement le nom de sa femme (Ahmosi), inscrit dans sa tombe ${ }^{24}$.

Époque : XVIII ${ }^{\text {eme }}$ dynastie, règne de Thoutmosis III.

Titre : Surveillant des mystères dans la maison du matin, scribe de livre des dieux et fils de nourricière ${ }^{25}$.

Document : Tombe d'Ahmose (TT 241) 26 .

\section{Document 6 :}

Nom : Mentiywy

Famille : fils du nourricière Hepu.

Époque: XVIII ${ }^{\text {ème }}$ dynastie, règne de Thoutmosis III et d'Aménophis II.

Titre : Majordome royal.

Document : La tombe de Mentiywy, (TT 172) ${ }^{27}$.

Il a pris son carrière comme un majordome dans les appartements royaux et a accompagné plus tard le roi dans ses campagnes. Le texte inscrit sur les murs de sa tombe explique qu'il a suivi le roi dans le Moyen-Orient et a traversé l'Euphrate. Mentiywy déclare qu'il ne s'est plus égaré le côté du roi sur le champ de bataille.

\footnotetext{
${ }^{22}$ PM I 1, p.229-230.

${ }^{23}$ G.Legrain,CGC.Statues et statuettes de rois et de particuliers,t.I,Le Caire1906,p.75-76,pl. 74. ${ }^{24}$ PM I 1, p.331.

25 A.Shorter, «The Tomb of Aahmose Supervisor of the Mysteries in the House of the Morning », JEA 16, 1930, p. 59-60.

${ }^{26}$ Ibid, p.54-62; PM I 1, p. 331.

${ }^{27}$ PM I 1, p. 279-280.
} 
Quand Aménophis II a suivi son père sur le trône, Mentiywy est resté au palais royal et a servi comme majordome royal.

\section{Document 7 :}

Nom : Paser

Famille : Sa mère Iahhotep, était nourricière durant le règne de Thoutmosis III $^{28}$.

Époque: XVIII ${ }^{\text {ème }}$ dynastie, règne de Thoutmosis III et d'Aménophis II.

Titre: Chef d'archers, compagnon de sa majesté, et fils du nourricière ${ }^{29}$.

Document : La tombe de Paser, $\left(\right.$ TT367) ${ }^{30}$.

\section{Document 8 :}

Nom : Kenamon

Famille : fils du nourricière Amenemopet.

Amenemopet a pris le titre de « $m n^{\complement} t$ wrt $n n b$ - $t 3 w y$ » la grande nourricière du maître de double pays ${ }^{31}$.

Époque : XVIII ${ }^{\text {eme }}$ dynastie, règne d'Aménophis II.

Titre : frère de lait du roi, «sn $n m n^{\complement} n n s w$ », frère de lait du maître de double pays ${ }^{32}$, «sn $n m n^{\Upsilon} y n n b-t 3 w y »$. chef du bovidé d'Amon ${ }^{33}$, "imy-r i ịw n Imn ».

chef de la grande maison de Perunefer ${ }^{34}$, « imy-r ${ }^{\complement}$ pr wr m prw-nfr ». Document: Tombe de Kenamon, (TT 93) ${ }^{35}$.

\section{Document 9 :}

Nom : Kaemheribsen

Famille : fils du nourricière Amenemopet.

${ }^{28}$ A.Fakhry, "Tomb of Paser (No.367 at Thebes)", ASAE 43, 1943, p.392.

${ }^{29}$ Ibid.

${ }^{30}$ PM I 1, p. 430-431.

${ }^{31}$ N.de G.Davies, The Tomb of Ken-Amun at Thebes, t.VII, London, 1930, p. 19; A.Radwan, "Die Darstellungen des regierenden Königs und seiner Familienangehorigen in den Privatgrabern der 18 Dynastie", MÄS 23, 1969, s. 91 f.

${ }^{32}$ H.Sottas, « Statuettes funèraires de la XVIII ${ }^{\mathrm{e}}$ Dynastie », Monuments et Mémoires 25,1922,p. 411.

${ }^{33}$ C.Roehrig, op.cit, p. 347.

${ }^{34}$ Ibid, p. 125. Perunefer est un palais de plaisir d'Aménophis II et de son père d'après Davies, et d'après Glanville c'est un chantier naval où le bateau de Thoumosis III a été construit.

${ }^{35}$ PM I 1,p.190-194; N.de G.Davies,The Tomb of Ken-Amun at Thebes,t.VII, London, 1930,p. 9-10. 
Sa mère était grande nourrice du maître de double pays ${ }^{36}$.

Époque : XVIII ${ }^{\text {ème }}$ dynastie, règne d'Aménophis II.

Titre : Troisième prophète d'Amon, " hm-ntr tpy 3 n'Imn », et chef du trésor du roi de la Haute Egypte ${ }^{37}$.

Document : La tombe de Kaemheribsen (TT 98) ${ }^{38}$.

Document 10 :

Nom : Mery

Famille : fils du nourricière Hunay.

Hunay a pris le titre de " $m n^{\top} t$ wrt $n n b-t 3 w y$ » la grande nourricière du maître de double pays ${ }^{39}$.

Époque : XVIII ${ }^{\text {ème }}$ dynastie, règne d'Aménophis II.

Titre : Premier prêtre d'Amon « hmm-ntr tpy n Imn »

Premier prêtre de Min « hm-ntr tpy $n$ Mnw Gbtyw »

Chef du bovidé d'Amon "imy-r iḥw n Imn »

Chef de la maison d'Amon « imy-r $r^{\odot} p r n$ Imn »

Chef du champ de grenier d'Amon ${ }^{40}$ « imy-re $3 h w t n$ Imn »

Document : Tombe de Mery, $\left(\right.$ TT 95) ${ }^{41}$.

\section{Document 11 :}

Nom : Sobekhotep

Famille: fils du Meryt, nourricière de la reine Tiaa, fille d'Aménophis II.

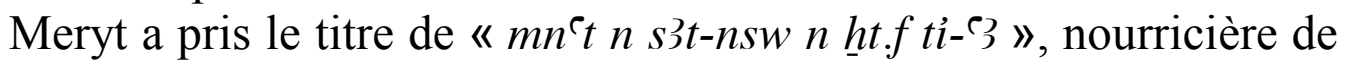
la fille du roi, de son corps, Tiaa ${ }^{42}$.

Époque : XVIII ${ }^{\text {ème }}$ dynastie, règne d'Aménophis II.

Titre : chef du Trésor du roi ${ }^{43}$, chef des bestiaux, chef des deux greniers et chef des travaux ${ }^{44}$.

${ }^{36}$ A.Fakhry, "Tombeau de Kaemheribsen", $A S A E$ 34, 1934, p.84; C.Roehrig, op.cit, p.119.

${ }^{37}$ Ibid.

${ }^{38}$ PM I 1, p. 204; A.Fakhry, op.cit, p.83-86.

${ }^{39}$ C.Roehrig, op.cit, p. 138 .

${ }^{40}$ C.Roehrig, op.cit, p.142.

${ }^{41}$ PM I 1, p. 195-196.

${ }^{42}$ A.Radwan, op.cit, s. 92 ; C.Roehrig, op.cit, p.227; PM I 1, p. 125-128.

${ }^{43}$ C.Roehrig, op.cit, p.221.

${ }^{44}$ R.Charles, « La statue-cube de Sobekhotep gouverneur du Fayoum », RdE 12, 1960, p. 11. 
Document :Tombe de Sobekhotep, (TT 63$)^{45}$, et une statue-cube de Sobekhotep, conservée au Musée de Marseille $\left(\mathrm{n}^{0} 208\right)^{46}$.

\section{Document 12 :}

Nom :Userhat

Famille : Sa mère était nourricière durant le règne d'Aménophis II. Époque : XVIII ${ }^{\text {ème }}$ dynastie, règne d'Aménophis II.

Titre : scribe royale.

Document : La tombe d'Userhat, (TT 56) ${ }^{47}$.

\section{Document 13:}

Nom :Mahu

Famille: Sa mère, Neith était nourricière royale durant le règne d'Aménophis II. Neith avait le titre de : « $m n^{\top} t$ wrt šdt ntrr 》 la grande nourrice, qui a nourrit le dieu.

Son père, Pehsukher, était lieutenant du roi et porteur d'étendard du maitre de double pays.

Époque : XVIII ${ }^{\text {ème }}$ dynastie, règne d'Aménophis II.

Titre : Deuxième prophète d'Amon.

Document : La tombe de Pehsukher, époux de Neith, (TT 88). Une scène représente Mahu faisant offrande à Neith et Pehsukher $^{48}$.

\section{Document 14:}

Nom : Nebenkemet

Famille : Sa mère était nourricière durant le règne d'Aménophis II. Époque : XVIII ${ }^{\text {ème }}$ dynastie, règne d'Aménophis II.

Titre : Chef du cabinet, porteur d'éventail et fils du nourricière ${ }^{49}$.

Document : La tombe de Nebenkemet, (TT 256) ${ }^{50}$.

\section{Document 15 :}

Nom : Menkheper

${ }^{45}$ PM I 1, p. 125-128.

${ }^{46}$ R.Charles, op.cit, p.1-26.

${ }^{47}$ PM I 1, p. 111-113.

${ }^{48}$ C.Roehrig, op.cit, p.173-174; PM I 1, p. 179-180.

${ }^{49}$ PM I 1, p. 340-341.

${ }^{50}$ Ibid. 
Famille: Sa mère Nay était nourricière durant le règne de Thoutmosis IV.

Époque : XVIII ${ }^{\text {ème }}$ dynastie, règne de Thoutmosis IV.

Titre: Scribe royale de la maison des enfants royal et fils du nourricière ${ }^{51}$.

Document : La tombe de Menkheper, (TT 258) ${ }^{52}$.

\section{Document 16 :}

Nom : Hekannefer

Famille: fils du Nebetkabeny, nourricière du princesse Sitamon (fille du roi Aménophis III).

Nebetkabeny a pris le titre de «mn`t ns3t-nsw ", nourricière de la fille du roi ${ }^{53}$.

Époque : XVIII ${ }^{\text {ème }}$ dynastie, règne d'Aménophis III.

Titre : Scribe dans le temple du dieu Osiris, «sš hwwt nț Wsir », et père du dieu d'Osiris «it nter $n W$ sir $\|^{54}$.

Document : stèle trouvé à Abydos (CG 34117) (fig.8).

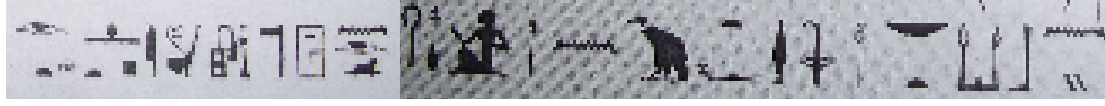

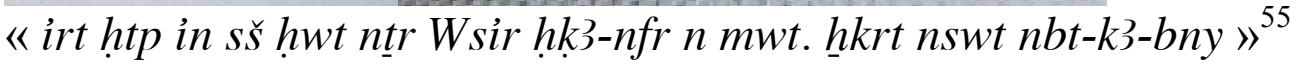

« Le scribe du temple d'Osiris, fait offrande à sa mère, la nourrice royale, Nebetakeny ».

\section{Document 17 :}

Nom : Benia, appellé Pahekmen

Famille : Ses parents Irtonena et Tirukak.

Époque : XVIII ${ }^{\text {ème }}$ dynastie.

Titre : Directeur des travaux et fils du nourricière.

Document : La tombe de Benia, (TT 343) ${ }^{56}$.

\section{Document 18 :}

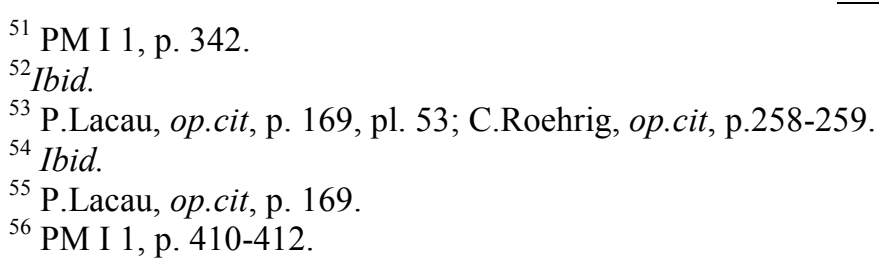


Nom : Kamosi, appellé Nentowaref

Époque : XVIII ${ }^{\text {ème }}$ dynastie.

Titre : Fils du nourricière.

Document : La tombe de Kamosi, (TT 398) ${ }^{57}$.

\section{Conséquences :}

D'après avoir étudié les différents documents, on conclut que le frère de lait a pris de grande position dans le pays à cause de son frère (le roi) et de sa mère (la nourricière royale).

Le roi avait choisi son frère de lait pour occuper des grandes positions administratives et sacerdotales; parmi ses positions: grand prêtre d'Amon, et chef du trésor du roi. Ses frères ont aussi pris le titre de frère de lait (doc.8), et fils de nourricière (doc .5, 7, $14,15,17,18)$.

Les fils du nourricière ont obtenu de grand intérêt, dont le roi Thoutmosis III avait choisi sa sœur de lait, Sataha (la fille de sa nourricière) pour être son épouse aussi que la reine. Ce choix retourne essentiellement à la grande confidence mise par les rois dans les fils des nourricières.

Parmi les grandes positions administratives et sacerdotales :

\begin{tabular}{|l|l|}
\hline Titres administratives & Titres sacerdotales \\
\hline Maire de Thinis (doc.1) & $\begin{array}{l}\text { Première prophète d'Amon } \\
(\text { doc.3, 4,10) }\end{array}$ \\
\hline $\begin{array}{l}\text { Surveillant des mystères dans la } \\
\text { maison du matin (doc.5) }\end{array}$ & $\begin{array}{l}\text { Deuxième prophète d'Amon } \\
(\text { doc.2, 13) }\end{array}$ \\
\hline Majordome royale (doc.6) & $\begin{array}{l}\text { Troisième prophète d'Amon } \\
\text { (doc.9) }\end{array}$ \\
\hline Chef d'archers (doc.7) & $\begin{array}{l}\text { Scribe de livres des dieux } \\
(\text { doc.5) }\end{array}$ \\
\hline Compagnon de sa majesté (doc.7) & $\begin{array}{l}\text { Première prêtre de Min } \\
\text { (doc.10) }\end{array}$ \\
\hline Chef de la grande maison de & \begin{tabular}{l} 
Chef de la maison d'Amon \\
\hline
\end{tabular}
\end{tabular}

${ }^{57}$ Ibid, p. 443. 


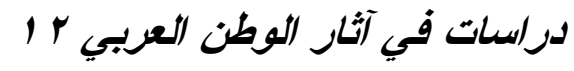

\begin{tabular}{|l|l|}
\hline Perunefer (doc.8) & (doc.10) \\
\hline Chef du trésor du roi (doc.9, 11) & $\begin{array}{l}\text { Chef du champ de grenier } \\
\text { d'Amon (doc.10) }\end{array}$ \\
\hline Chef des bestiaux (doc.11) & $\begin{array}{l}\text { Chef du bovidé d'Amon } \\
\text { (doc.8) }\end{array}$ \\
\hline Chef des deux greniers (doc.11) & $\begin{array}{l}\text { Scribe dans le temple du dieu } \\
\text { Osiris (doc.16) }\end{array}$ \\
\hline Scribe royale (doc.12) & Père du dieu d'Osiris (doc.16) \\
\hline Chef du cabinet (doc.14) & \\
\hline Porteur d'éventail (doc.14) & $\begin{array}{l}\text { Scribe royale de la maison des } \\
\text { enfants (doc.15) }\end{array}$ \\
\hline Directeur des travaux (doc.11,17) & \\
\hline
\end{tabular}

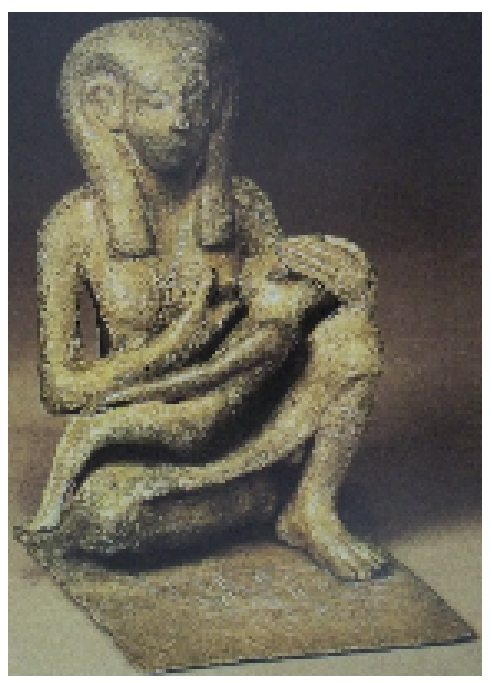

Fig.1 : Femme nourricière de la Moyenne Empire, cuivre, Musée de Berlin (14078).

R.Schulz, M.Seidel, Egypt the world of the Pharaos, China, 2007, p. 409. 


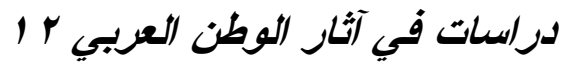

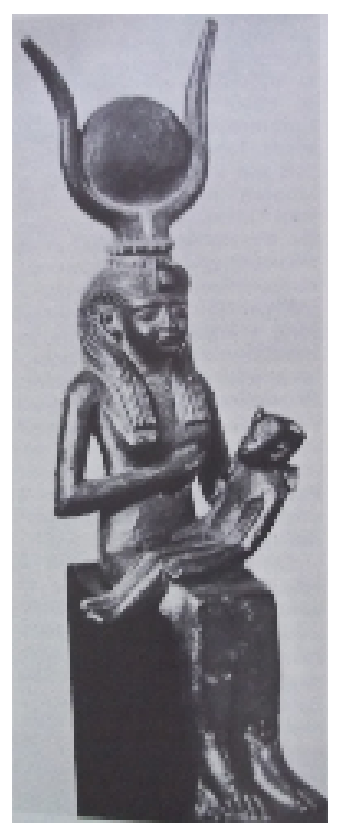

Fig.2 : La déesse Isis allaité Horus.

G.Posener, S.Sauneron et J.Yoyotte, Dictionnaire de la civilisation égyptienne, Paris, 1988, p. 140.

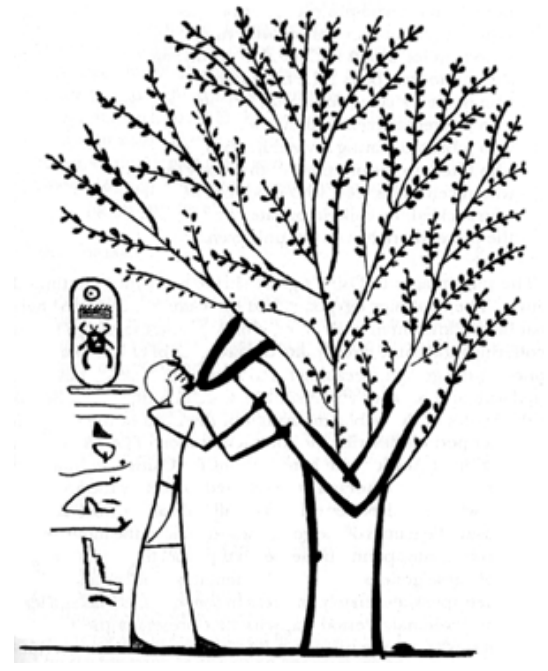

Fig.3 : Le roi Thoutmosis III allaité par Isis sous la forme d'un arbre sacré.

G.Posener, S.Sauneron et J.Yoyotte, Dictionnaire de la civilisation égyptienne, Paris, 1988, p. 145. 


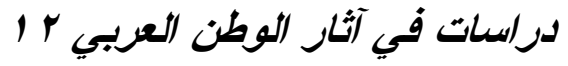

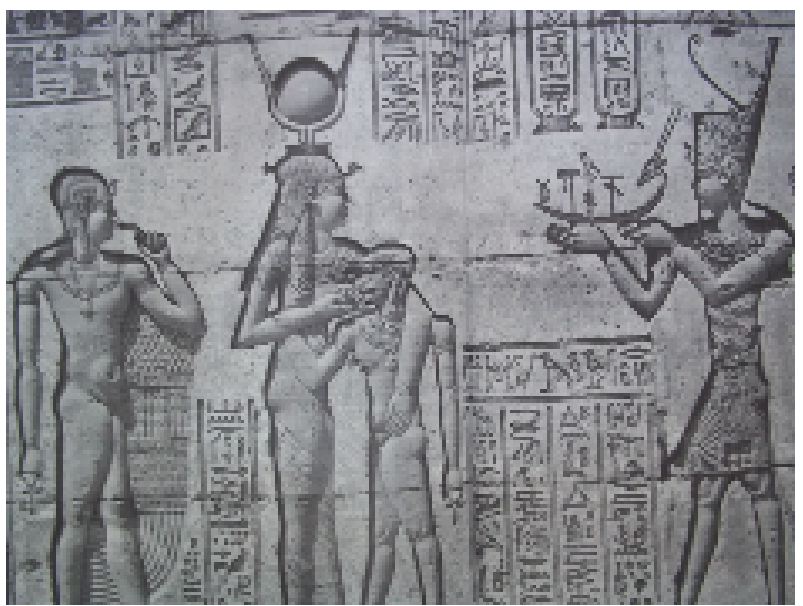

Fig.4 : La déesse Hathor entrain d'allaiter le roi, dans le mammisi du temple d'Hathor à Dendérah.

B.Watterson, Gods of Ancient Egypt, Hong Kong, 1996, p. 116-117.
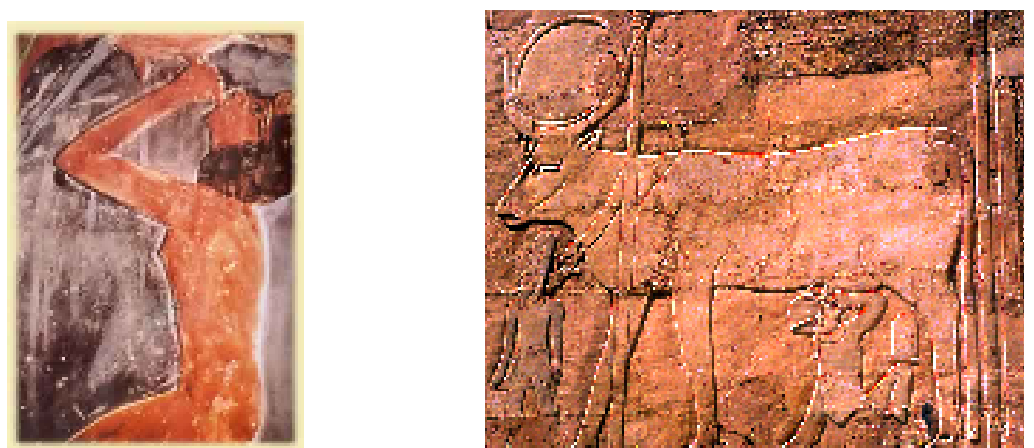

Fig.5: Thoutmosis III entrain d'allaiter de la déesse vache Hathor, dans la chapelle de Thoutmosis III à Deir el-Bahari.

M.Werbouck, Le temple d'Hatshepsout à Deir el Bahri, Brussel, 1948. 
دراسات في آثار الوطن العربي با 1

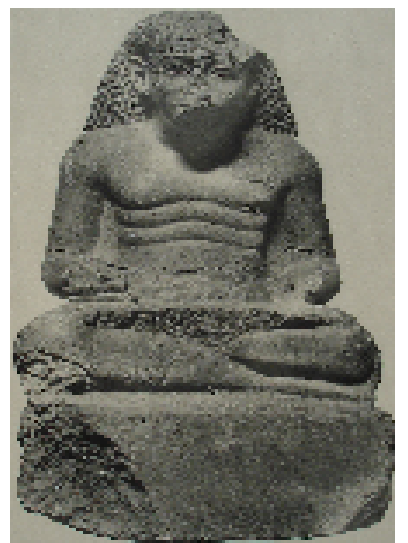

Fig.7 : statue de Menkheperresonb G.Legrain, CGC. Statues et statuettes de rois et de particuliers, t.I,

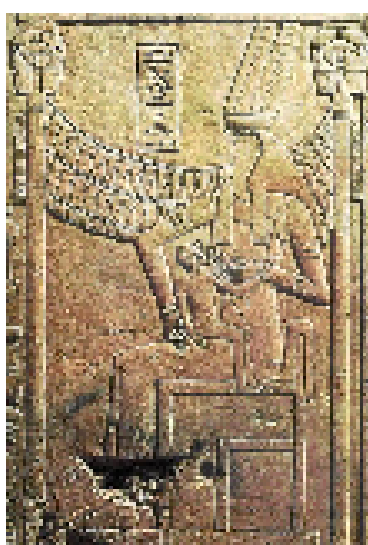

Fig.6 : La déesse Rénénoutet. W.Wreszinski, Atlas, pl. 198.

Le Caire 1906, pl. 74.

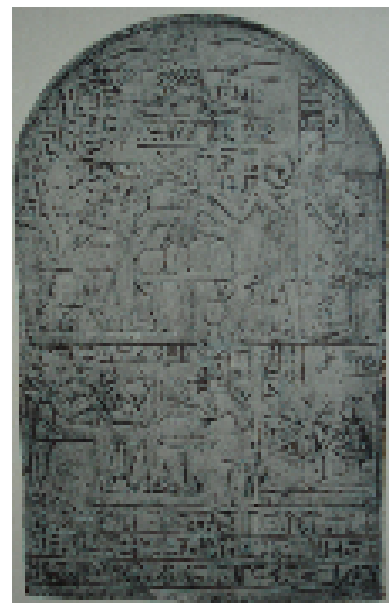

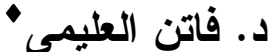

Fig.8 : Stèle d'Abydos.

P.Lacau, Stèles du Nouvel Empire, pl. LIII.

$$
\text { اخو في الرضاعة }
$$

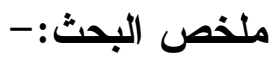

أطلق لقب المرضعة الملكية لأول مرة على عدد من السيدات منذ بداية الأسرة الثامنة عشرة و استمر ذلك حتى نهاية عهد اخناتون حيث توقف اللقب عن تماما عن الظهور . • كلية السياحة و الفنادق - جامعة قناة السويس. 


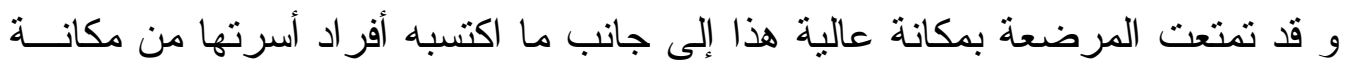

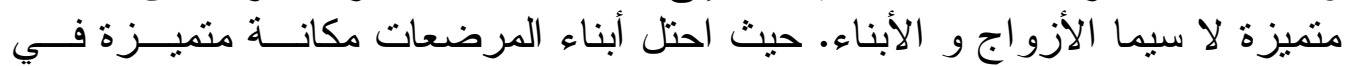

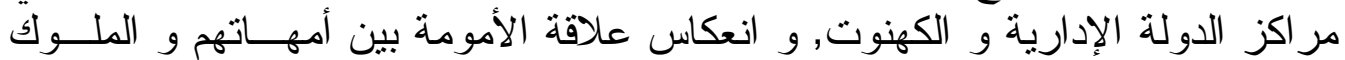

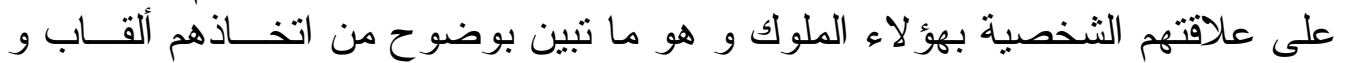

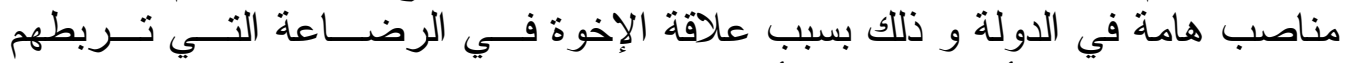

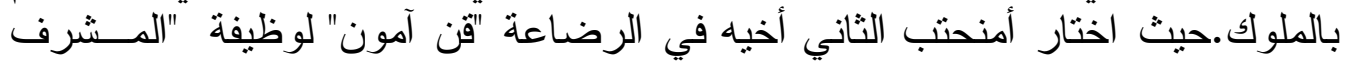

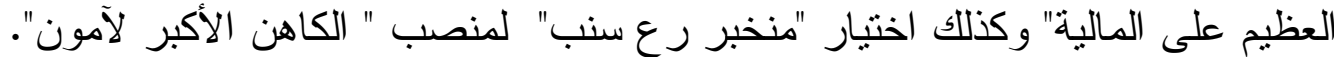

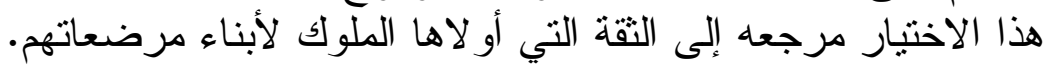
هذا البحث يهذف إلى إلقاء الضوء على لقب اخو في الرضاعة التهاء و المناصب و الألقاب التي اتخذو ها هؤ لاء الأشخاص بلاء لضبب إنهم أبناء المرضعات. 